\title{
Gastric intramucosal pH: an indicator of weaning outcome from mechanical ventilation in COPD patients
}

\author{
G. Bouachour, M-P. Guiraud, J-P. Gouello, P-M. Roy, P. Alquier
}

Gastric intramucosal $\mathrm{pH}$ : an indicator of weaning outcome from mechanical ventilation in COPD patients. G. Bouachour, M-P. Guiraud, J-P. Gouello, P-M. Roy, P. Alquier. (CERS Journals Ltd 1996.

ABSTRACT: The aim of this study was to determine whether gastric intramucosal $\mathrm{pH}$ (pHim) and/or gastric intramucosal carbon dioxide tension $\left(\mathrm{PCO}_{2}, \mathrm{im}\right)$ measured by tonometry can be used to predict the success of weaning in chronic obstructive pulmonary disease (COPD) patients. Twenty six consecutive COPD patients, undergoing mechanical ventilation for acute respiratory failure and satisfying the criteria of weaning from mechanical ventilation with nasogastric tonometer in place, were studied.

Arterial blood gas values and $\mathrm{PCO}_{2}$,im were measured $24 \mathrm{~h}$ before $(\mathrm{H}-24)$, just before (H0), and after $20 \mathrm{~min}$ of a weaning trial on T-piece (H20min). Weaning failure was defined as the development of respiratory distress and/or arterial blood gas impairments during the first $2 \mathrm{~h}$ of spontaneous breathing on T-piece, or reintubation within $24 \mathrm{~h}$ after extubation.

Between the weaning failure $(n=6)$ and weaning success $(n=20)$ groups, there were no differences in blood gas analysis readings at $\mathrm{H}-24$ and $\mathrm{HO}$ before the weaning period, age, Simplified Acute Physiology Score (SAPS) on admission, SAPS on the day of weaning trial, and duration of ventilation. Clinical status, tonometric and arterial gasometric data were similar at $\mathrm{H}-24$ and $\mathrm{HO}$ in all patients. During mechanical ventilation, $\mathrm{pHim}$ was $\leq 7.30$ in patients who failed weaning and $>7.30$ in patients who were successfully weaned $(p<0.001 ; 100 \%$ sensitivity and specificity). The threshold value for $\mathrm{PCO}_{2}$,im of $8.0 \mathrm{kPa}(60 \mathrm{mmHg})$ represents a clear demarcation with respect to outcome before the weaning trial. $\mathrm{PCO}_{2}$,im values during mechanical ventilation are significantly different $(p<0.001)$ between patients who were successfully weaned and those who were not $(6.9 \pm 0.9$ vs $9.9 \pm 1.1 \mathrm{kPa}(51.9 \pm 6.7$ vs $74.3 \pm 8.0 \mathrm{mmHg}$, respectively)). At $\mathrm{H} 20 \mathrm{~min}$, pHim and $\mathrm{PCO}_{2}$,im were still statistically different between the weaning failure and the weaning success group.

We conclude that measurement of gastric intramucosal pH (or gastric intramucosal carbon dioxide tension) represents a simple and accurate index to predict weaning outcome in chronic obstructive pulmonary disease patients before attempting weaning.

Eur Respir J., 1996, 9, 1868-1873.
Medical Intensive Care Unit, Centre Hospitalier Universitaire, Angers, France.

Correspondence: G. Bouachour Service de Réanimation Médicale Centre Hospitalier Universitaire 49033 Angers Cedex 01

France

Keywords:

Chronic obstructive pulmonary disease gastric intramucosal $\mathrm{pH}$

weaning from mechanical ventilation weaning index

Received: July 241995

Accepted after revision May 281996
Many different indices, such as vital capacity, minute ventilation, maximal inspiratory pressure, ratio of respiratory frequency to tidal volume, airway occlusion pressure, and arterial blood gas values [1], have been proposed to predict the outcome of weaning from mechanical ventilation. However, they do not always accurately predict the success of a weaning trial leading to extubation in elderly [2] or intensive care patients [3]. In patients with chronic obstructive pulmonary disease (COPD) a shortterm failure is easily detected through clinical investigation or blood gas analysis during a weaning trial of spontaneous breathing. However, early prediction of long-term ability to sustain spontaneous breathing after extubation is not easy. Failure to wean from mechanical ventilation may be attributed to various problems, including impaired pulmonary gas exchange, decreased central drive for respiration, and respiratory muscle weakness or fatigue due to the imbalance between the increa- sed work of breathing and the inability to meet the increased ventilatory demand [4]. Early recognition of an imbalance between energy demand and supply, even before the weaning trial, may lead to reconsideration of the time of weaning, investigation of factors that may be responsible for the failure, or institution of a partial mode of ventilatory support [5].

The gut is one of the tissues most sensitive to hypoxia, whatever its mechanisms [6-8]. In critically ill patients, despite haemodynamic stability or compensated shock, the gastrointestinal tract can develop mucosal acidosis [9]. This is thought to reflect an underlying tissue oxygen debt, and suggests inadequacy between tissue oxygen uptake and oxygen delivery $[10,11]$. Thus, the gut mucosa was considered to be the "canary of the body" because it provides early warning of the presence of shock, just as the collapse of a canary provided coal miners with an early warning of the presence of carbon 
monoxide [12]. In agreement with this concept, we hypothesized that in ventilated COPD patients with apparent criteria for weaning success, an unknown regional hypoxia, such as gastric mucosal acidosis, might lead to unsuccessful attempts at weaning from mechanical ventilation. We conducted a prospective study in COPD patients who had been artificially ventilated for acute respiratory failure and were medically stable, to evaluate the gastric intramucosal $\mathrm{pH}$ as a predictor of the outcome of weaning.

\section{Material and methods}

\section{Patients}

Twenty six consecutive patients ( 9 females and 17 males) aged 42-86 yrs (mean \pm sD $68 \pm 9$ yrs) were included in the study. They all had a medical history of COPD, confirmed by respiratory function tests performed before, or 1-9 months after, the acute respiratory failure (ARF). In all patients, ARF was caused by pulmonary infection. Patients with ARF related to musculoskeletal, neuromuscular, neurological, cardiac disease or any sign of thromboembolism were not included. The Simplified Acute Physiology Score (SAPS) for intensive care unit patients [13] was recorded on admission and on the day of study. All patients gave their informed consent.

\section{Study design}

Before starting the study, the patients were mechanically ventilated using assist-control ventilation (Servo 900C; Siemens-Elema, Lund, Sweden). Each patient was evaluated by the attending physician in view of a weaning trial. The weaning decision was primarily based on the following clinical and gasometric requirements: improvement in/or resolution of the underlying cause of ARF; a core temperature below $38.5^{\circ} \mathrm{C}$; relief from sedation; correction of electrolyte disorders; a haemoglobin level $>10 \mathrm{~g} \cdot \mathrm{dL}^{-1}$; stable haemodynamics; and arterial oxygen tension $\left(\mathrm{Pa}_{\mathrm{a}} \mathrm{O}_{2}\right) \geq 8 \mathrm{kPa}(60 \mathrm{mmHg})$ (with inspiratory oxygen tension $\left(F \mathrm{I}, \mathrm{O}_{2}\right) \leq 0.4$ and positive end-expiratory pressure (PEEP) $\leq 5 \mathrm{cmH}_{2} \mathrm{O}$ ). All the patients underwent a weaning trial of spontaneous breathing via a T-piece for $2 \mathrm{~h}$. The ability of the patients to sustain spontaneous breathing was evaluated during disconnection from the ventilator with supply of supplemental oxygen and humidification of gas on the T-piece. Minute ventilation $\left(V^{\prime} \mathrm{E}\right)$ was measured with a calibrated spirometer attached to the endotracheal tube. The average tidal volume $(V \mathrm{~T})$ was calculated by dividing the $V^{\prime} \mathrm{E}$ into the respiratory frequency $(f \mathrm{R})$. Extubation was performed at the end of the trial for patients who did not develop criteria of weaning failure. The findings of the current investigation were not made available to the primary physician and, thus, did not influence the physician's decision regarding extubation.

For the purpose of this study, weaning success was defined as the ability to sustain spontaneous breathing for $\geq 24 \mathrm{~h}$ after extubation. Weaning failure was defined as: 1) the necessity to reinstitute ventilatory support at the end of the weaning trial because of the development of one or more of the following criteria: $f \mathrm{R} \geq 30$ breaths $\cdot \mathrm{min}^{-1}$, diaphoresis, activity of accessory inspiratory muscles, changes in cardiac frequency $(f \mathrm{C})$ or systolic blood pressure (SBP) $\geq 20 \%$, an increase in arterial carbon dioxide tension $\left(\mathrm{Pa}, \mathrm{CO}_{2}\right)$ of $\geq 1.1 \mathrm{kPa}(8 \mathrm{mmHg})$, arterial $\mathrm{pH}(\mathrm{pHa})$ $\leq 7.32$ or a decrease in $\mathrm{pHa}$ of $\geq 0.08, P \mathrm{a}, \mathrm{O}_{2}<8 \mathrm{kPa}(60$ $\mathrm{mmHg}$ ) with an $\mathrm{FI}, \mathrm{O}_{2} \geq 0.5$; or 2) reintubation within 24 $\mathrm{h}$ of discontinuation of ventilatory support due to the deterioration of respiratory condition. Arterial blood gas values and gastric intramucosal $\mathrm{pH}$ were measured at three time-points: 1) $24 \mathrm{~h}$ before the day of the weaning trial (H-24); 2) just before the weaning period ( $\mathrm{H} 0)$; and 3 ) after the first $20 \mathrm{~min}$ of the spontaneous breathing T-piece trial (H20min).

\section{Measurements of gastric intramucosal pH}

Gastric intramucosal $\mathrm{pH}$ was determined indirectly using a gastrointestinal sump tonometer (TRIP tonometer; Tonometrics, Inc., Worcester, MA, USA). Following nasogastric insertion, the position of the tonometer in the stomach was confirmed radiographically. The anaerobic gastric balloon was filled with $2.5 \mathrm{~mL}$ of $0.9 \%$ saline at room temperature. Equilibration periods of $30 \mathrm{~min}$ for the two first measurements and 20 min during the weaning trial were allowed between tonometer saline loading and sampling. Simultaneous anaerobic samples of the tonometered saline and arterial blood were obtained and analysed immediately for saline carbon dioxide tension $\left(\mathrm{PCO}_{2}\right)$ and arterial blood bicarbonate, using a standard blood gas analyser (Radiometer Copenhagen ABL 330). The gastric intramucosal $\mathrm{pH}$ (pHim) was computed using the following modification of the Henderson-Hasselbalch equation:

$$
\text { pHim }=6.1+\log _{10} \times \frac{\text { arterial } \mathrm{HCO}_{3}^{-}}{\mathrm{F} \times 0.03 \times \text { tonometered saline } \mathrm{PCO}_{2}}
$$

where $\mathrm{F}$ is a time-dependent factor for partially equilibrated samples. In vitro studies have shown that measured normal saline $\mathrm{PCO}_{2}$ requires an adjustment, which is dependent on the equilibration period, to determine the steady-state adjusted $\mathrm{PCO}_{2}$ (gastric intramucosal $\mathrm{PCO}_{2}$ $\left.\left(P_{\mathrm{CO}_{2}}, \mathrm{im}\right)\right)$. The values of $\mathrm{F}$, provided by the manufacturer, were 1.36 and 1.24 for equilibration periods of 20 and $30 \mathrm{~min}$, respectively. To improve the accuracy of the pHim measurement, all patients received histamine receptor $\left(\mathrm{H}_{2}\right)$ blocking agents (two oral doses of $150 \mathrm{mg}$ ranitidine. $24 \mathrm{~h}^{-1}$ ), and enteral feeding was stopped for the duration of the data collection period [14]. Because the assumption that arterial bicarbonate equals gut interstitial bicarbonate is controversial $[15,16]$, indices such as the ratios between $P_{C_{2}}$, im and $P \mathrm{a}, \mathrm{CO}_{2}\left(\mathrm{PCO}_{2}, \mathrm{im} / \mathrm{Pa}_{\mathrm{a}} \mathrm{CO}_{2}\right)$ and the differences between the arterial and gastric $P_{\mathrm{CO}_{2}}$ $\left(\mathrm{PCO}_{2}, \mathrm{im}-\mathrm{Pa}, \mathrm{CO}_{2}\right)$ were recorded $[7,16]$.

\section{Statistical analysis}

All data are presented as mean \pm SD. Statistical analysis was performed by analysis of variance (ANOVA) for repeated measures on two factors (group and time). In 
the tests showing significant $\mathrm{F}$ ratios, subsequent pairwise comparisons were tested for significance with the Bonferroni adjustment. Threshold values obtained in this study were values that yielded the least false positive and false negative results. A true positive result was defined as occurring when a test predicted successful weaning and weaning actually succeeded. A false positive result was defined as occurring when a test predicted successful weaning but weaning actually failed. A false negative result was defined as occurring when a test predicted weaning failure but weaning actually succeeded. A true negative result was defined as occurring when a test predicted weaning failure and weaning actually failed. Standard formulae were used to calculate the sensitivity (true positives/(true positives + false negatives)), specificity (true negatives/(true negatives + false positives)), positive predictive value (true positives/(true positives + false positives)) and negative predictive value (true negatives/(true negatives + false negatives)). The areas under the receiver operating characteristic (ROC) curve of different variables, and comparison between these areas, were calculated by the method of HANLEY and McNeIL [17]. A probability of less that 0.05 was considered significant.

\section{Results}

Twenty patients were successfully weaned and all were discharged from the intensive care unit in good clinical condition. Six patients failed the weaning trial and required the reinstitution of mechanical ventilation without having been extubated. After failure of the weaning trial on a T-piece, four of the six patients were weaned using pressure support ventilation for 3, 10, 22 and 25 days from the beginning of the study. One patient remained definitively ventilator-dependent and one patient died of nosocomial pneumonia. None of the patients in the weaning failure group had acute left ventricular dysfunction when spontaneous breathing was resumed during the further weaning attempts, as shown by right-sided cardiac catheterization or by echocardiography. The two groups did not differ in blood gas analysis readings at $\mathrm{H}-24$ and $\mathrm{HO}$ before the weaning period, or in age, SAPS on admission, SAPS on the day of weaning trial, and ventilation duration (table 1).

In all patients, during the $24 \mathrm{~h}$ period of observation before the weaning trial, at $\mathrm{H}-24$ and $\mathrm{H} 0$, no significant changes of the tonometric and arterial gasometric data were found. Comparing the tonometric data before the weaning trial and at $20 \mathrm{~min}$ of spontaneous breathing on T-piece (table 1), pHim was significantly higher and $\mathrm{PCO}_{2}$,im significantly lower in the successfully weaned patients than that of the patients with weaning failure. The mean values of $f \mathrm{C}$ and SBP were also significantly different between the two groups. No statistical differences were found for $P \mathrm{CO}_{2}, \mathrm{im} / P \mathrm{a}, \mathrm{CO}_{2}$ and $P \mathrm{CO}_{2}, \mathrm{im}-\mathrm{Pa}, \mathrm{CO}_{2}$ during the weaning trial, at $\mathrm{H} 20 \mathrm{~min}$, between the two groups. When these two groups were considered separately, significant changes for gasometric data were observed in the successfully weaned group but not in the weaning failure group. There was significant decrease in $\mathrm{pHa}$ and $\mathrm{pHim}(\mathrm{p}<0.005$ and $\mathrm{p}<0.05$, respectively), and $P \mathrm{a}, \mathrm{CO}_{2}$ and $\mathrm{PCO}_{2}$,im (fig. 1, table 1) increased significantly $(\mathrm{p}<0.005$ and $\mathrm{p}<0.05$, respectively) during the first $20 \mathrm{~min}$ of the trial in patients who were successfully weaned. $P \mathrm{CO}_{2}, \mathrm{im} / P \mathrm{a}, \mathrm{CO}_{2}$ and $P \mathrm{CO}_{2}, \mathrm{im}-P \mathrm{a}, \mathrm{CO}_{2}$ did not change

Table 1. - Characteristics and clinical, blood gas, tonometric data and weaning parameters of 26 patients on mechanical ventilation prior to weaning $(\mathrm{HO})$ and 20 min after weaning $(\mathrm{H} 20 \mathrm{~min})$

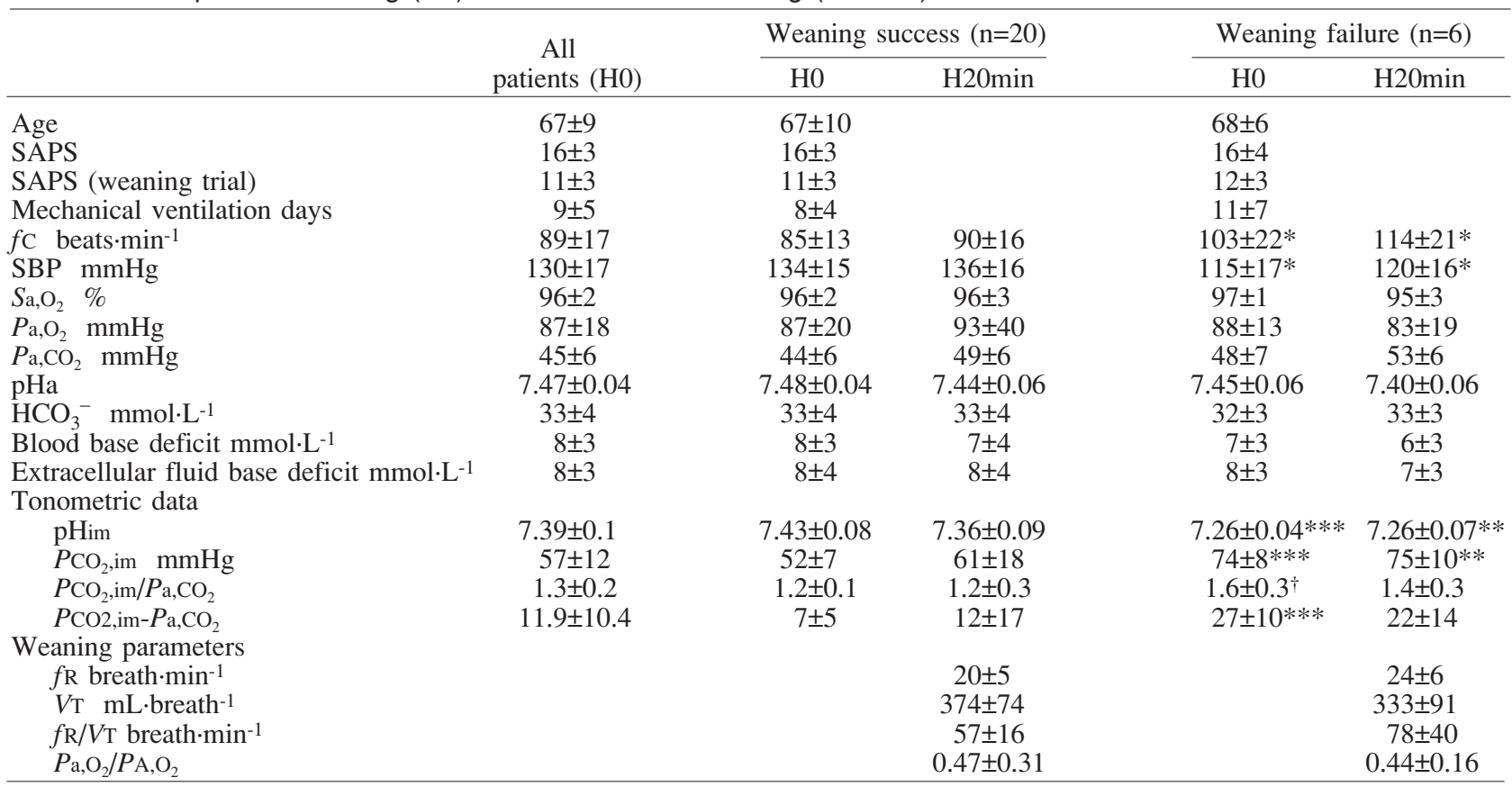

Data are presented as mean \pm SD. COPD: chronic obstructive pulmonary disease; SAPS: Simplified Acute Physiological Score; $f$ C: cardiac frequency; SBP: systolic blood pressure; $f \mathrm{R}$ : respiratory frequency; $V \mathrm{~T}$ : tidal volume; $F_{\mathrm{I}, \mathrm{O}_{2}}$ : inspiratory oxygen fraction; $\mathrm{Sa}_{\mathrm{a}} \mathrm{O}_{2}$ : arterial oxygen saturation; $\mathrm{Pa}, \mathrm{O}_{2}$ : arterial oxygen tension; $\mathrm{Pa}_{\mathrm{a}} \mathrm{CO}_{2}$ : arterial carbon dioxide tension; pHa: arterial $\mathrm{pH} ; P_{\mathrm{CO}}, \mathrm{im}$ : gastric intramucosal carbon dioxide tension; $\mathrm{pHim}$ : gastric intramucosal $\mathrm{pH} ;{\mathrm{PA}, \mathrm{O}_{2}}_{2}$ : alveolar oxygen tension. $1 \mathrm{mmHg}=0.133 \mathrm{kPa}$. $*: \mathrm{p}<0.05 ; * *: \mathrm{p}<0.01 ; \dagger \mathrm{p}<0.005 ; * * *: \mathrm{p}<0.001$ versus weaning success at the same time points. 
a)

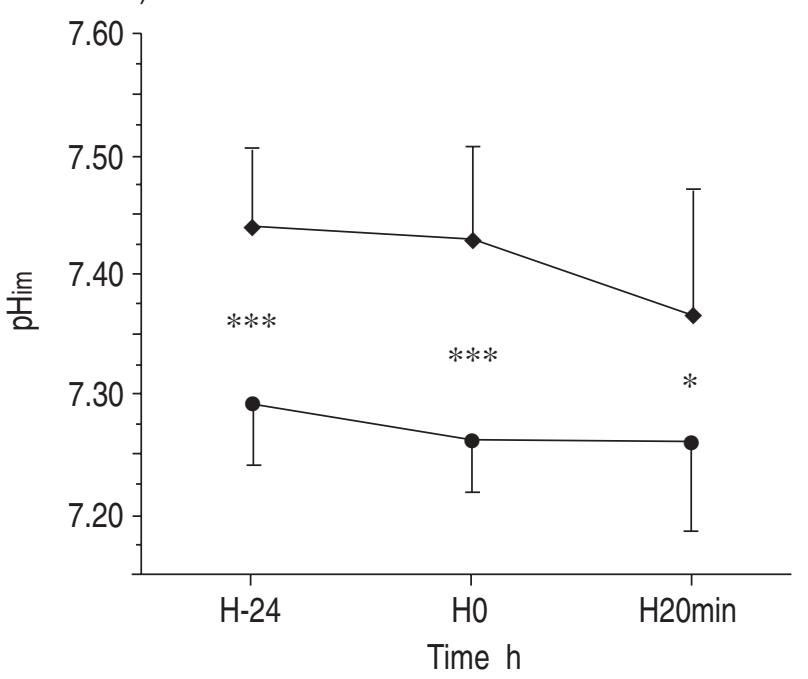

b)

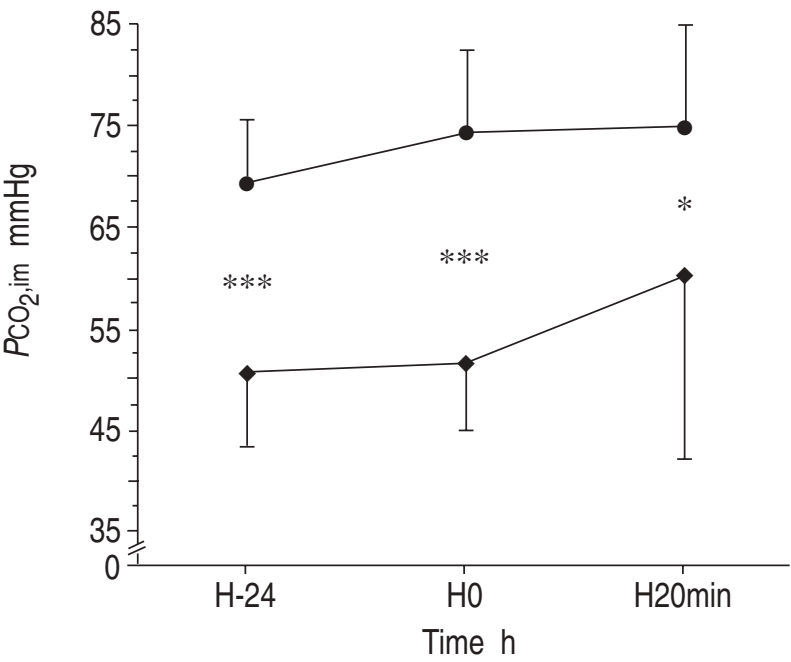

Fig. 1. - Changes in: a) gastric intramucosal $\mathrm{pH}(\mathrm{pHim})$; and b) carbon dioxide tension $\left(\mathrm{PCO}_{2}, \mathrm{im}\right)$ in 26 chronic obstructive pulmonary disease (COPD) patients $24 \mathrm{~h}$ before $(\mathrm{H}-24)$ and just before $(\mathrm{H} 0)$ the weaning period, and after the first $20 \mathrm{~min}$ of spontaneous breathing (H20min). Data are mean \pm sD. —— : weaning success; —- : weaning failure. *: $\mathrm{p}<0.05 ; * * *: \mathrm{p}<0.001$ comparing weaning success and failure groups. $1 \mathrm{mmHg}=0.133 \mathrm{kPa}$.

significantly. Only the $f \mathrm{R}$ increased similarly $(\mathrm{p}<0.05)$ in the two groups during the weaning trial.

The threshold values used for $\mathrm{pHim}$ and $\mathrm{PCO}_{2}$,im were 7.30 and $8 \mathrm{kPa}(60 \mathrm{mmHg})$, respectively. These thresholds were chosen because they had the lowest number of false classifications. Sensitivity, specificity, positive and negative predictive values of the variables obtained by the tonometer in predicting outcome of weaning are presented in table 3. During mechanical ventilation, before the weaning trial, $\mathrm{pHim}$ was the most accurate predictor of the weaning outcome, while $P \mathrm{CO}_{2}$,im at the same time was slightly less accurate. The 20 patients who were successfully weaned all had a pHim $>7.30$, while the six patients who experienced weaning failure had a pHim $<7.30$. Twenty minutes after the onset of the weaning trial, pHim and $\mathrm{PCO}_{2}$,im still predicted the weaning outcome, but with a low negative predictive value. Tonometric data and other commonly measured indices are
Table 3. - Sensitivity, specificity, positive and negative predictive values of each index

\begin{tabular}{llcll}
\hline Index & Sensitivity & Specificity & PPV & NPV \\
\hline$V \mathrm{~T} \geq 325 \mathrm{~mL} \cdot$ breath $^{-1}$ & 0.9 & 0.4 & 0.75 & 0.67 \\
$f \mathrm{R} / V \mathrm{~T} \leq 105$ breath $^{2} \mathrm{~min}^{-1} \cdot \mathrm{L}$ & 1 & 0.4 & 0.77 & 1 \\
$P \mathrm{a}, \mathrm{O}_{2} / P \mathrm{PA}, \mathrm{O}_{2} \geq 0.35$ & 0.67 & 0.4 & 0.77 & 0.28 \\
$P \mathrm{CO}_{2}, \mathrm{im} \leq 60 \mathrm{mmHg}(\mathrm{H} 0)$ & 0.95 & 1 & 1 & 0.86 \\
$P \mathrm{CO}_{2}, \mathrm{im} \leq 60 \mathrm{mmHg}$ & 0.6 & 1 & 1 & 0.43 \\
$(\mathrm{H} 20 \mathrm{~min})$ & & & & \\
$\mathrm{pHim}>7.30(\mathrm{H} 0)$ & 1 & 1 & 1 & 1 \\
$\mathrm{pHim}>7.30(\mathrm{H} 20 \mathrm{~min})$ & 0.9 & 0.67 & 0.9 & 0.67 \\
\hline
\end{tabular}

H0: measured just before weaning trial; H20min: measured after 20 min of weaning trial; PPV: positive predictive value; NPV: negative predictive value. For further definitions see legend to table $1.1 \mathrm{mmHg}=0.133 \mathrm{kPa}$.

Table 4. - Area under ROC curves of weaning variables after $20 \mathrm{~min}$ of spontaneous breathing on T-piece

\begin{tabular}{lc}
\hline Variables & $\begin{array}{l}\text { Area under } \\
\text { ROC curve }\end{array}$ \\
\hline$V \mathrm{~T}$ & $0.62 \pm 0.16$ \\
$f \mathrm{R} / V \mathrm{~T}$ & $0.62 \pm 0.17$ \\
$P_{\mathrm{a}, \mathrm{O}_{2} / P \mathrm{~A}, \mathrm{O}_{2}}$ & $0.49 \pm 0.02$ \\
$P \mathrm{CO}_{2}, \mathrm{im}$ & $0.85 \pm 0.08$ \\
$\mathrm{pHim}$ & $0.91 \pm 0.06$ \\
\hline
\end{tabular}

ROC: received operating characteristic. For further definitions see legends to tables 1 and 2 .

compared in table 3 . The classical threshold values were used, which have been established previously in the literature [1]. Ten patients in the success group and five patients in the failure group had available data to be considered for the weaning parameters. The most accurate predictors of the weaning outcome were pHim and $P \mathrm{CO}_{2}$,im, while the traditional indices were less accurate. The areas under the ROC curves of each of the variables are tabulated in table 4. Comparisons between ROC areas showed significant differences $(\mathrm{p}<0.001)$ between each area of the tonometric variables and each area of the other measured indices.

\section{Discussion}

This study demonstrates that gastric tonometric data, such as pHim and $\mathrm{PCO}_{2}$,im, are accurate predictors of weaning outcome in COPD patients. The threshold value for pHim of 7.30 represents a clear demarcation with respect to outcome. This result is consistent with the result of another study [18] in a nonselected intensive care population that pHim is $\leq 7.30$ in the weaning failure patients. However, in this study [18], a gastrointestinal tonometer was not used and gastric intramural $\mathrm{pH}$ was calculated with the modified Henderson-Hasselbalch equation using the value of the gastric juice $\mathrm{PCO}_{2}$. The major finding of the current study is that there is a significant difference in pHim and $\mathrm{PCO}_{2}$,im between weaning success and weaning failure COPD patients during mechanical ventilation before the weaning trial of spontaneous breathing on T-piece. In contrast, MoHSENIFAR et al. [18] did not find a statistical difference in pHim and $\mathrm{PCO}_{2}$,im values before the weaning trial, between the patients in 
whom weaning failed and the patients who were later successfully weaned. Nevertheless, baseline pHim was lower and baseline $\mathrm{PCO}_{2}$,im was higher in their weaning failure group. We suspect that the apparent lack of difference between the two groups was due to the populations studied, since five of the 29 patients in their study were not COPD patients.

During spontaneous ventilation or different modes of weaning, oxygen cost of breathing in COPD patients is increased [5, 19]. The major contribution of increased oxygen cost is likely to be the increased work of breathing and decreased efficiency of the respiratory muscles. Examination of respiratory muscle function during weaning from mechanical ventilation has shown that diaphragmatic muscular fatigue occurred rapidly in groups of patients failing to wean $[5,20]$. This increased respiratory muscle energy demand, with no possibility of supply, creates an oxygen debt leading to the weaning failure. Furthermore, if there is an unknown and pre-existing oxygen debt during mechanical ventilation, in combination with occult tissue ischaemia, attempts to wean the patient will not succeed.

Estimation of pHim by the tonometric technique appears to be a sensitive indicator of splanchnic oxygenation [21], and the value of pHim is closely related to the gastric mucosal blood flow [22]. Patients in whom weaning failed had no evident cause of gastrointestinal hypoxia, such as the sepsis syndrome, hypovolaemia or left ventricular failure, while they were mechanically ventilated. However, the higher $f \mathrm{C}$ and lower SBP noted in these patients are probably associated with an increase in catecholamine release. Increased sympathetic activity during weaning has been related $[5,19,23,24]$ to plasma noradrenaline levels significantly higher in patients in whom weaning failed [23]. In the current study, this assumption is supported by the apparently enhanced $f \mathrm{C}$ and SBP in patients with weaning failure. We hypothesize that patients in whom weaning failed had an inadequate oxygen delivery to splanchnic organs due to a reduction of splanchnic blood flow in relation to stress hormone secretion, leading to the development of intramucosal acidosis [25].

Various stressful situations in COPD patients, such as respiratory drive insufficiency, increased respiratory workload and respiratory muscle weakness, that cause respiratory pump failure, have been indicated [4]. The acidosis of the digestive tract mucosa appeared to be an alarm index to detect unexpected dysoxia in patients with apparently stable clinical status. This has been demonstrated in large series of critically ill patients, where a low or a falling pHim in the first $24 \mathrm{~h}$ of hospitalization in an intensive care unit has a strong prognostic value for the outcome $[6,10]$. In the present study, a low pHim suggests that the cause of the ARF is not totally eliminated or there is an underlying illness not yet resolved. A blood flow diversion from the splanchnic bed to other organs suffering from hypoxia could explain gastric mucosal acidosis [18, 26, 27]. In these conditions, weaning from mechanical ventilation involves a major energy demand, which cannot be satisfied, to sustain the workload of the respiratory muscles. Therefore, in mechanically ventilated COPD patients with positive weaning criteria and $\mathrm{pHim}<7.30$, the causes of weaning failure must be found, otherwise a partial mode of ventilatory support will be necessary until the patient sustains spontaneous breathing allowing extubation [5].

Validity of the tonometric measurements while the patients were mechanically ventilated was assessed by similar values of pHim and $\mathrm{PCO}_{2}$,im at $24 \mathrm{~h}$ before and immediately before the weaning trial. Because physicians attending the patients were not informed of the results of the study, no therapeutic interventions were made to correct $\mathrm{pHim}$. One may wonder whether the correction of pHim would have led to success of the weaning trial. In patients in whom weaning succeeded, significant changes in pHim or $\mathrm{PCO}_{2}$,im were observed during the first 20 min of spontaneous breathing, whereas no change appeared in patients in whom weaning failed. These results are apparently in contradiction with the study of Mohsenifar et al. [18]. They found that those patients that could not be weaned from assisted mechanical ventilation in a nonselected critically ill population experienced significant decreases in gastric mucosal $\mathrm{pH}$ during weaning, while patients who were successfully weaned showed no change in gastric mucosal $\mathrm{pH}$. During weaning, COPD patients developed hypoventilation of various degrees progressively reaching their basal acid-base status. BENJAMIN et al. [28] have shown, in canine models of acute respiratory acidosis, that systemic hypercapnia directly elevates $\mathrm{PCO}_{2}$,im. In the weaning success group of the present study, the drop in pHim was entirely due to the rise in $\mathrm{PCO}_{2}$,im, since it occurred despite a stable arterial bicarbonate concentration. Other acute and severe systemic acid-base imbalances [15] may influence the value of $\mathrm{pHim}$ which do not reflect the actual gastric acid-base status.

The analysis of the difference between, or the ratio of, gastric mucosal and arterial $\mathrm{PCO}_{2}$ did not help in the interpretation of the data $[7,16]$. Indeed, the value of base deficit in blood and extracellular fluid has been claimed to give results similar to those obtained by tonometry [29]. The equilibration period used for tonometry to measure $P_{C_{2}}$, im was $20 \mathrm{~min}$, which is a short time in which to obtain the steady-state adjusted $P_{C_{2}}$,im during a dynamic process such as a weaning trial. This short equilibration period may explain why $\mathrm{PCO}_{2}$,im did not change in the weaning failure group, which already had a high $P_{C_{2}}$,im value before the weaning trial. However, in critically ill patients, the longer periods required for tonometry are not practical in acute situations [10] and may be avoided by using a correcting time-dependent factor to assess $\mathrm{PCO}_{2}$,im.

In this study, the simple weaning criteria, such as blood gases and clinical variables, were inadequate for the prediction of successful weaning in the COPD patients. Commonly used weaning indices (respiratory frequency, tidal volume, the ratio of respiratory frequency/tidal volume, the ratio of $\mathrm{Pa}, \mathrm{O}_{2} /$ alveolar oxygen tension $\left(\mathrm{PA}, \mathrm{O}_{2}\right)$ compared to the weaning tonometric indices, were not good predictors of weaning failure in the present study group. The areas under the ROC curves for $\mathrm{pHim}$ and $\mathrm{PCO}_{2}$,im were significantly different from those of other weaning variables. Although the usefulness of numerous weaning indices in COPD patients has been reported in several studies [30-32], the major advantage of this current method lies in its simplicity. The measurements can be obtained easily and without complicated equipment.

In conclusion, the results of this study indicate that 
during the immediate period before the discontinuation of mechanical ventilation, gastric intramucosal $\mathrm{pH}$ higher than 7.30 and gastric intramucosal carbon dioxide tension lower than $8 \mathrm{kPa}(60 \mathrm{mmHg})$ best separated the weaning success from the weaning failure chronic obstructive pulmonary disease patients. Throughout the study, the patients who failed to wean had persistently lower gastric intramucosal $\mathrm{pH}$ and gastric intramucosal carbon dioxide tension values before the weaning trial than did the successfully weaned patients. However, studies on a larger number of patients will be necessary to confirm these results.

Acknowledgements: The authors thank the medical intensive care unit nursing staff for their invaluable assistance and co-operation.

\section{References}

1. Yang KL, Tobin MJ. A prospective study of indexes predicting the outcome of trials of weaning from mechanical ventilation. N Engl J Med 1991; 324: 1445-1450.

2. Krieger BP, Ershowsky PF, Becker DA, Gazeroglu HB. Evaluation of conventional criteria for predicting successful weaning from mechanical ventilatory support in elderly patients. Crit Care Med 1989; 17: 858-861.

3. Fiastro JF, Habib MP, Shon BY, Campbell SC. Comparison of standard weaning parameters and the mechanical work of breathing in mechanically-ventilated patients. Chest 1988; 94: 232-238.

4. Lemaire F. Difficult weaning. Intensive Care Med 1993; 19: S69-S73.

5. Brochard L, Harf A, Lorino H, Lemaire F. Inspiratory pressure support prevents diaphragmatic fatigue during weaning from mechanical ventilation. Am Rev Respir Dis 1989; 139: 513-521.

6. Doglio GR, Pusajo JF, Egurrola MA, et al. Gastric mucosal $\mathrm{pH}$ as a prognostic index of mortality in critically ill patients. Crit Care Med 1991; 19: 1037-1040.

7. Mythen MG, Webb AR. The role of gut mucosal hypoperfusion in the pathogenesis of postoperative organ dysfunction. Intensive Care Med 1994; 20: 203-209.

8. Fiddian-Green RG. Associations between intramucosal acidosis in the gut and organ failure. Crit Care Med 1993; 21: S103-S107.

9. Gutierrez G, Palizas F, Doglio G, et al. Gastric intramucosal $\mathrm{pH}$ as a therapeutic index of tissue oxygenation in critically ill patients. Lancet 1992; 339: 195-199.

10. Maynard N, Bihary D, Beale R, et al. Assessment of splanchnic oxygenation by gastric tonometry in patients with acute circulatory failure. JAMA 1993; 270: 12031210.

11. Gutierrez G, Clark C, Brown ST, Price K, Ortiz L, Nelson C. Effect of dobutamine on oxygen consumption and gastric mucosal $\mathrm{pH}$ in septic patients. Am J Respir Crit Care Med 1994; 150: 324-329.

12. Dantzker DR. The gastrointestinal tract. the canary of the body? JAMA 1993; 270: 1247-1248.

13. LeGall JR, Loirat $\mathrm{Ph}$, Alperovitch A, et al. A simplified acute physiology score for ICU patients. Crit Care Med 1984; 12: 975-977.

14. Heard SO, Helsmoortel CM, Kent JC, Shahnarian A Fink MP. Gastric tonometry in healthy volunteers: effects of ranitidine on calculated intramural pH. Crit Care Med 1991; 19: 271-274
15. Benjamin E, Polokoff E, Oropello JM, Leibowitz AB, Iberti TJ. Sodium bicarbonate administration affects the diagnostic accuracy of gastrointestinal tonometry in acute mesenteric ischemia. Crit Care Med 1992; 20: 1181-1183.

16. Lee MH. Gastric mucosal $\mathrm{pH}$ as a prognostic index of mortality in critically ill patients. Crit Care Med 1992; 7: 1074-1075

17. Hanley JA, McNeil BJ. A method of comparing the areas under receiver operating characteristic curves derived from the same case. Radiology 1983; 148: 839-843.

18. Mohsenifar Z, Hay A, Hay J, Lewis MI, Koerner SK. Gastric intramural $\mathrm{pH}$ as a predictor of success or failure in weaning patients from mechanical ventilation. Ann Intern Med 1993; 119: 794-798.

19. Annat GJ, Viale JP, Dereymez CP, Bouffard YM, Delafosse BX, Motin JP. Oxygen cost of breathing and diaphragmatic pressure-time index: measurement in patients with COPD during weaning with pressure support ventilation. Chest 1990; 98: 411-414.

20. Pourriat JL, Lamberto C, Hoang PH, Fournier JL, Vasseur B. Diaphragmatic fatigue and breathing pattern during weaning from mechanical ventilation in COPD patients. Chest 1986; 90: 703-707.

21. Grum CM, Fiddian-Green RG, Pittenger GL, Grant BJB, Rothman ED, Dantzker DR. Adequacy of tissue oxygenation in intact dog intestine. J Appl Physiol: Respirat Environ Exercise Physiol 1984; 56: 1065-1069.

22. Antonsson JB, Boyle CC, Kruithoff KL, et al. Validity of tonometric measures of gut intramural $\mathrm{pH}$ during endotoxemia and mesenteric occlusion in pigs. Am J Physiol 1990; 259: G519-G523.

23. Oh TE, Bhatt S, Lin ES, Hutchinson RC, Low JM. Plasma cathecholamines and oxygen consumption during weaning from mechanical ventilation. Intensive Care Med 1991; 17: 199-203.

24. Kennedy SK, Weintraub RM, Skillman JJ. Cardiorespiratory and sympathoadrenal responses during weaning from controlled ventilation. Surgery 1977; 82: 233-240.

25. Porter JM, Sussman MS, Bulkley GB. Splanchnic vasospasm in circulatory shock. In: Martson A, Bulkley GB, Fiddian-Green RG, Haglund U, eds. Splanchnic Ischemia and Multiple Organ Failure. London, Edward Arnold, 1989; pp. 73-88.

26. Hussain SN, Roussos C. Distribution of respiratory muscle and organ blood flow during endotoxic shock in dogs. J Appl Physiol 1985; 59: 1802-1808.

27. Magder S, Erian R, Roussos C. Respiratory muscle blood flow in oleic acid-induced pulmonary edema. $J$ Appl Physiol 1986; 6: 1849-1856.

28. Benjamin E, Hannon EM, Oropello JM, Stern PM, Premus G, Iberti TJ. Effects of systemic respiratory acidosis on gastrointestinal tonometry. Anesthesiology 1992; 77: A307.

29. Boyd O, Mackay CJ, Lamb G, Bland JM, Grounds RM, Bennett ED. Comparison of clinical information gained from routine blood-gas analysis and from gastric tonometry for intramural pH. Lancet 1993; 341: 142-146.

30. Conti G, De Blasi R, Pelaia P, et al. Early prediction of successful weaning during support ventilation in COPD patients. Crit Care Med 1992; 20: 366-371.

31. Menziens R, Gibbons W, Goldberg P. Determinants of weaning and survival among patients with COPD who require mechanical ventilation for acute respiratory failure. Chest 1989; 95: 398-405.

32. Sassoon CSH, Te TT, Mahutte CK, Light RW. Airway occlusion pressure: an important indicator for successful weaning in patients with chronic obstructive pulmonary disease. Am Rev Respir Dis 1987; 135: 107-112. 